GA-A24056

\title{
DESIGN, FABRICATION, INSTALLATION AND TESTING OF IN-VESSEL CONTROL COILS FOR DIII-D
}

\author{
by \\ P.M. ANDERSON, C.B. BAXI, A.G. KELLMAN, E.E. REIS, \\ and J.I. ROBINSON
}




\section{DISCLAIMER}

This report was prepared as an account of work sponsored by an agency of the United States Government. Neither the United States Government nor any agency thereof, nor any of their employees, makes any warranty, express or implied, or assumes any legal liability or responsibility for the accuracy, completeness, or usefulness of any information, apparatus, product, or process disclosed, or represents that its use would not infringe privately owned rights. Reference herein to any specific commercial product, process, or service by trade name, trademark, manufacturer, or otherwise, does not necessarily constitute or imply its endorsement, recommendation, or favoring by the United States Government or any agency thereof. The views and opinions of authors expressed herein do not necessarily state or reflect those of the United States Government or any agency thereof. 
GA-A24056

\title{
DESIGN, FABRICATION, INSTALLATION AND TESTING OF IN-VESSEL CONTROL COILS FOR DIII-D
}

\author{
by \\ P.M. ANDERSON, C.B. BAXI, A.G. KELLMAN, E.E. REIS, \\ and J.I. ROBINSON
}

This is a preprint of a paper presented at the 22nd Symposium on Fusion Technology, September 9-13, 2002, in Helsinki, Finland, and to be published in Fusion Engineering and Design.

\author{
Work supported by \\ the U.S. Department of Energy \\ under Contract DE-AC03-99ER54463
}




\section{ABSTRACT}

Since 1995, DIII-D has performed correction of magnetic field imperfections using a set of six external picture frame coils located on the vessel mid-plane. Recently, these coils have also demonstrated significant benefits when used for feedback of the resistive wall mode, an instability that limits the plasma performance at high beta. Modeling has shown that substantial performance improvements can be achieved by installing new coils inside the vessel and expanding the poloidal coverage above and below the mid-plane. Two prototype internal coils were installed in 2001 and have been tested successfully. Installation of a set of twelve internal coils and magnetic sensors in the DIII-D tokamak is to be completed in December 2002.

The design requirement for the new coil system was to maximize the magnetic field at the plasma edge, operate with a frequency range of dc to $1000 \mathrm{~Hz}$, and fit behind the existing graphite wall tiles. The coil design adopted and installed is a water-cooled hollow copper conductor insulated with polyamide and housed inside a stainless steel tube that forms a vacuum boundary. The coil is rigidly mounted to the inside of the vacuum vessel.

The primary challenge in the design of these coils was in joining of both the copper conductor and the stainless tube without overheating the polyamide insulator. 


\section{BACKGROUND}

DIII-D has performed correction of magnetic field imperfections since 1995 using a set of six external picture frame coils located on the vessel mid-plane. Recently, these coils have also demonstrated significant benefits when used for feedback of the resistive wall mode (RWM), an instability that limits the plasma performance at high beta [1]. A study was conducted to evaluate the performance of an expanded array of 18 coils $(6$ on the midplane, 6 each above and below the midplane). The study considered concepts replicating existing external coil technology or installing new technology coils inside the vacuum vessel in addition to the six existing external coils. Table 1 compares coil design features.

Modeling using the VALEN 3D code has shown that substantial performance improvements can be achieved by installing new coils inside the vessel and expanding the poloidal coverage both above and below the mid-plane. The advantage of the in-vessel design over the ex-vessel design is due to the closer proximity to the plasma, better field penetration, lower inductance and more uniform geometry. The expanded coverage provides a better match to the mode structure of the RWM, improving our ability to stabilize it. Comparison of a full set of 18 internal coils with a reduced set of 12 ( 6 midplane coils removed) showed no significant benefit to the 18 coil set. Twelve new internal coils with $B_{p}$ sensors should allow for operation near the ideal wall $\beta$ limit, a key element in the advanced tokamak mission of DIII-D. 


\section{DESIGN GOALS}

The key design requirements for the new coil system are to maximize the magnetic field at the plasma edge, operate with a frequency range of dc to $1000 \mathrm{~Hz}$, and fit in the space behind the existing graphite wall tiles to avoid any plasma contact. The specified voltage standoff is $1000 \mathrm{Vdc}$ from conductor to vessel ground. This provides a factor of 3 margin above the expected peak voltage of $\sim 400 \mathrm{~V}$; the coil power supply is capable of a peak voltage of $300 \mathrm{~V}$ while disruptions can add up to $60 \mathrm{~V}$ across the coil terminals. Disruption induced currents can add $4 \mathrm{kA}$ (17 kA for a faulted coil) to the normal $5 \mathrm{kA}$ coil current, so the mechanical attachment of the coil to the vessel must be adequate to prevent damage to in-vessel components in the event of a faulted coil condition. The in-vessel coil environment requires a robust design due to high cyclic electromagnetic forces in vacuum and temperatures to $350^{\circ} \mathrm{C}$ during vessel baking.

Figure 1 shows the two prototype coils that were installed in DIII-D in 2001. The full invessel coil set will consist of two sets of six coils each located on the inside of the outer wall on conical surfaces above and below the midplane. The coils are single turn with a conductor length of $5 \mathrm{~m}$ and an area of $1 \mathrm{~m} \mathrm{sq}$. In order to minimize error fields and electromagnetic forces, the radially oriented power and cooling water feeds are coaxial. The coils are shielded from the plasma by the

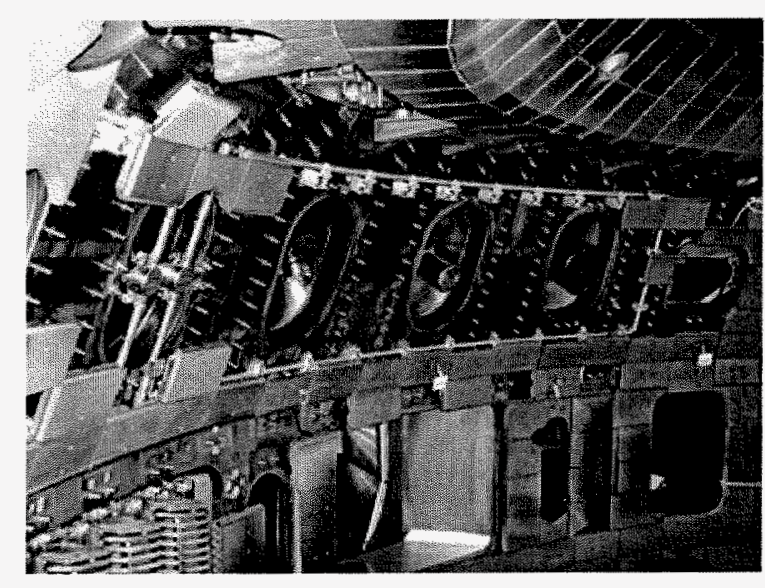

Fig. 1. Installation of 2 prototype 1 coils, October 2001. plasma facing graphite tiles that are shown partially installed. 


\section{DESIGN SOLUTION}

Because the size of the ports on DIII-D would not permit a fully assembled coil to be passed into the vessel, the coil either had to be formed in the vessel from a straight section introduced through a port or assembled together inside the vessel from smaller subassemblies. The space available for the coil beneath the graphite wall tiles is approximately a $29 \mathrm{~mm}$ by $29 \mathrm{~mm}$ sq cross section. Due to the space limitation imposed by the PF tiles, there is no room to allow for coil turns to cross each other and the coil is limited to single turn construction.

The in-vessel coil design adopted and installed is shown in Fig. 2. It is water-cooled hollow copper conductor ( $14.4 \mathrm{~mm}$ o.d.) insulated with polyamide and housed inside a stainless steel tube (19 mm o.d.) that forms a vacuum boundary. The polyamide insulating layer is comprised of $0.5 \mathrm{~mm}$ Kapton tape (50\% overlap), a $1.7 \mathrm{~mm}$ thick Duport vespel SP-1 spacer, and an additional layer of Kapton tape. The coil conductor system is engineered to operate up to $7 \mathrm{kA}$ dc steady-state with cooling water flow of $5.5 \mathrm{~m} / \mathrm{s}$. Shop

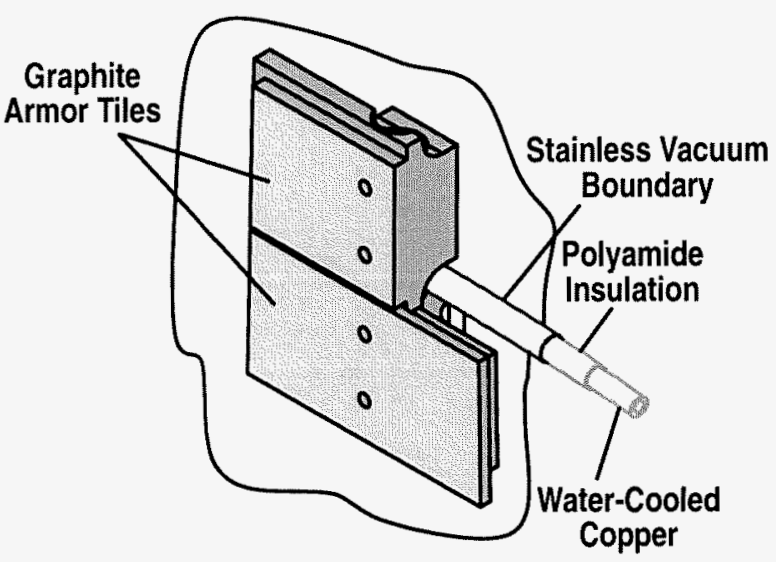

Fig. 2. Construction of internal control coils for a set of 12 single turn, actively water-cooled, copper loops. The coils will be located above and below the midplane and behind the protective armor tiles.

fabrication uses in-air induction brazing of the oxygen free copper conductor joints at the corners of each coil. The copper and polyamide insulation is encased in a welded 304 stainless steel vacuum barrier that is the only material exposed to vessel vacuum. Each coil is fully formed on a mockup in the shop. This process allows the coil to be passed into the vessel in three pieces; a lower conductor assembly, an upper conductor assembly and a $35 \mathrm{~mm}$ diameter concentric lead assembly. This design required in-vessel joining of copper with three induction brazes and six orbital welds of the stainless vacuum jacket.

The design provides a double barrier of copper and stainless against water leakage into the tokamak. The polyamide selected, DuPont Vespel SP-1, is hydroscopic and contains about $1 \%$ by mass of water at room conditions. This moisture is evolved as the material is heated to $350^{\circ} \mathrm{C}$ during vessel baking. The insulator is located between the copper and the stainless and could be exposed to atmosphere at both ends of the conductor outside of the vessel. In order to detect water leaks in the copper or leaks through the stainless into the vessel, the insulation space is sealed in two places outside the vessel using machined polyamide and " $O$ " rings. During the initial bake of the vessel, this space is vacuum pumped to remove moisture and gases that evolve. 
After cool down, dry nitrogen gas is back filled to about 0.7 bar, and sealed off. The pressure in this trapped volume is monitored to detect either water leaks through the copper (higher pressure) or stainless sheath leaks to the vacuum (lower pressure). During vessel baking, the cooling water in the coils is replaced with dry nitrogen in order to limit oxidization of the copper. 


\section{DEVELOPMENT ISSUES}

The primary challenge in the design of these coils was in joining of both the copper conductor and the stainless tube without overheating the polyamide insulator. Early testing indicated that the hollow copper conductor could be brazed in air without overheating the polyamide insulation located $50 \mathrm{~mm}$ from the braze joint. This process depends on rapid localized heating of the copper. An axial thermal gradient of over $815^{\circ} \mathrm{C}$ at the braze to less than $400^{\circ} \mathrm{C}$ at the polyamide is required. This was achieved with localized induction heating with about $10 \mathrm{~kW}$ for about $13 \mathrm{~s}$. Similar polyamide overheating problems were evident when TIG welding the stainless steel tubing which contacted the polyamide. A solution was developed using automated orbital welding of the stainless steel tube to specially designed joints that distribute the welding heat throughout a large mass which is thermally remote from the polyamide. A second issue with the welding process is trapping of gas pressure within the stainless sheath due to outgassing of the polyamide during the welding process. This caused weld blowout near the closure of the orbital weld. This problem was corrected on the prototype coils with manual weld repair. Gas vents were developed for the production coils to prevent blowout. These $2.5 \mathrm{~mm}$ holes are then plugged with a set-screw and seal welded manually. The brazing and welding processes are performed both outside and inside of the vacuum vessel. 


\section{THERMAL AND STRESS ANALYSIS}

Thermal analysis of the resistive heating and water cooling of the copper as well as transient temperatures during vessel baking is reasonably straightforward. The copper and water cross sections for the $14.4 \mathrm{~mm}$ o.d. conductor were optimized to maximize dc steady-state current without exceeding a water outlet temperature of $90^{\circ} \mathrm{C}$ for water flow of $5.5 \mathrm{~m} / \mathrm{s}$. The $5 \mathrm{~m}$ long conductor coil can handle $7 \mathrm{kA}$ steady-state, limited by $53^{\circ} \mathrm{C}$ water temperature increase. Steadystate is reached after $8 \mathrm{~s}$ of constant power input.

Stress analysis was done for $\mathrm{I} \times \mathrm{B}$ forces and thermal stresses during vessel bake-out. With alternating current at frequencies as high as $1 \mathrm{kHz}$, there are concerns for high cycle fatigue of the copper and stainless. The coil conductor is clamped rigidly to the Inconel vessel wall at intervals less than $180 \mathrm{~mm}$. Although finite element analysis predicted a first resonance at $980 \mathrm{~Hz}$, none were detected during frequency sweeping to $1000 \mathrm{~Hz}$ in a strong magnetic field. The cyclic bending stress in the copper due to a $5 \mathrm{kA}$ coil current reacting with the $2.2 \mathrm{~T}$ toroidal field is $35 \mathrm{Mpa}$ and compares with a room temperature yield strength of $69 \mathrm{Mpa}$ for annealed copper. This provides an expected fatigue life of greater that $10^{10}$ cycles, sufficient for $10^{6}$ full current, $10 \mathrm{~s}$ pulses at $1 \mathrm{kHz}$. Of greater concern is the low cycle fatigue experienced during baking cycles that occur about 10 times a year. The temperature rise from 20 to $350^{\circ} \mathrm{C}$ takes $5 \mathrm{hrs}$ and the temperatures of the Inconel vessel, and the coil components of stainless, polyamide and copper are reasonably uniform due to conduction between materials. Thermal stresses develop during baking due to differences in the rate of thermal expansion between the Inconel 625 wall, stainless 304 sheath and the oxygen free copper conductor. These thermal expansion rates are $0.0000176 /{ }^{\circ} \mathrm{C}$ for stainless and copper and $0.0000155 /{ }^{\circ} \mathrm{C}$ for Inconel. The main concern is for compressive stresses that develop in the copper as the thermal expansion of the copper is restrained by the stainless and Inconel. The copper is fully annealed during each bake cycle to $350^{\circ} \mathrm{C}$. With this type of thermal cycling, the thermal stresses shake down to acceptable levels with the highest stresses occurring during the first bake since most of the copper starts in the hard, high strength condition. Based on a finite element elastic analysis of the coil/vessel structure, the total strain at the worst case OFHC elbow joint during cooldown from bakeout is $0.14 \%$. This total strain applied to the stress curves for annealed OFHC translates to an alternating plastic strain of $0.04 \%$. The allowable number of cycles at this plastic strain range is 10,000 cycles based on the lower bound fatigue curve of Ref. [2]. The two prototype coils have experienced about twelve bake cycles to $350^{\circ} \mathrm{C}$ without problems. 


\section{PROTOTYPE TESTING}

The plan for initial operation of the twelve internal coils in 2003 is to power them with supplies capable of 5000 A. The two prototype coils installed in Summer 2001 have been tested to the full capability of those supplies. This included the following:

- Coil cooling tests: $4.5 \mathrm{kA}$ dc for $7 \mathrm{~s}$ which generated $22.7 \mathrm{~kW}$ of heat in the coil as compared to the steady-state design rating of $59 \mathrm{~kW}$. No anomolous heating was observed. A slight increase in coil resistance was measured $(\sim 200 \% @ 1 \mathrm{kHz})$ by water flow calorimetry. This increase is expected due to the decreasing skin depth in the copper conductor at $1 \mathrm{kHz}$.

- Power testing: $4.5 \mathrm{kA}$ delivered from $\mathrm{dc}-300 \mathrm{~Hz}$ as limited by the power supply with delivered current decreasing to $1.5 \mathrm{kA}$ at $1000 \mathrm{~Hz}$ as limited by the inductance of the supply system cabling.

- Mechanical Testing: frequency sweeping from 0 to $1000 \mathrm{~Hz}$ with maximum tokamak poloidal and toroidal fields to monitor for coil mechanical resonances. None were detected by strain gages on the stainless coil sheath. Operation at $4.5 \mathrm{kA}, 250 \mathrm{~Hz}$ for 12,500 cycles at maximum poloidal and toroidal fields to perform fatigue tests. No failures were observed.

- Hi pot testing: the installed coils were tested to $4.8 \mathrm{kV}$ for early mechanical assemblies before brazing or welding. The installed coils were tested to $1.2 \mathrm{kV}$ after installation. Prototype developmental component parts were tested to failure that occurred between 6 and $9 \mathrm{kV}$. AC hi pot testing was performed with a $\pm 400 \mathrm{~V}, 10 \mathrm{kHz}$ square wave for $\sim 36$ hrs. with no insulation failure.

Based on successful manufacturing, installation, and operation of the prototype coils, we are confident that the full 12 coil set should be ready for operation in 2003 . 


\section{REFERENCES}

[1] A.G. Kellman, "Recent Progress from the DIII-D Program," to be published in Fusion Engineering and Design.

[2] "Properties of Copper and Copper Alloys at Gryogenic Temperatures," NIST Monograph 177, National Institute of Standards and Technology, (1992) 4-22. 


\section{ACKNOWLEDGMENT}

Work supported by U.S. Department of Energy under Contract DE-AC03-99ER54463. 